\title{
Designing a Brokerage Platform for the Delivery of E-government Services to the Public
}

\author{
Dimitra Pappa and Constantin Makropoulos \\ National Centre for Scientific Research "Demokritos" \\ Terma Patriarchou Gregoriou E' \\ Agia Paraskevi Attikis, Greece \\ \{dimitra, cmakr\}@dat.demokritos.gr
}

\begin{abstract}
The demand for modernizing government to the benefit of the citizens calls for new approaches to traditional practices. The use of technology in government can enhance the access to and the delivery of public services, thus improving the overall efficiency of government. Online joined-up government refers to the integration of public services from a customer of public services' point of view. In line with this "consumer-centric" approach, the principal objective of a one-stop government portal is to facilitate seamless access to integrated services that are shaped around everyday life episodes and business situations and comprise service offerings from several public entities. The implementation of e-Government involves not only a profound transformation in the way government interacts with the governed but also the reinvention of its internal processes and organisation. Back-office interconnection and interoperability are key enablers.
\end{abstract}

\section{Introduction}

The introduction of Information \& Communication Technologies (ICT) and the spread and improvement of communication networks accelerate the transformation of government and its methods of operation. The use of electronic technologies in government opens up many possibilities for improving services to citizens and businesses, for increasing efficiency and reforming traditional paper processes.

Traditionally, government work is divided into sectors (health, education, finance etc) and the resulting responsibilities are assigned to several institutions, each one of which produces and delivers a number of services to the public. However it is often the case that users (i.e. citizens and enterprises), when confronted with a particular life or business situation, need a set of services often originating from several different public authorities. In the present situation the user needs to have full knowledge of the overall process to be followed: the authorities involved, the services that need to be invoked at each authority, the input required for each service, the order of invocation etc.

In order to better serve the demands of citizens and enterprises, public administration is faced with the challenge of adopting a "consumer-centric" approach, providing joined-up services that are user-driven (i.e. are organised and delivered the way the user wants). 
Electronic service delivery offers huge opportunities to meet the needs of citizens. The development of unified online access points, where various public authorities collaborate for the provision of integrated services that are structured in a cohesive, theme-based manner and transcend conventional agency boundaries, is regarded as a means to enhance the overall effectiveness of government. Portals of this type offering information and services based on "life-" and "business-episodes" (i.e. everyday life and business situations) aim at providing citizens and businesses with the opportunity to interact easily and seamlessly with all the involved authorities and/or departments, thus hiding away the organisational complexity, the fragmentation of responsibilities, and the underlying interdependencies of the public sector.

Online public offerings fall into two major categories: information and services. Online public information refers to the distribution of official government information, while the term online public services refers to online government applications that are offered to groups external to government such as citizens and businesses. Public services are the concrete products and services an external customer is re-questing.

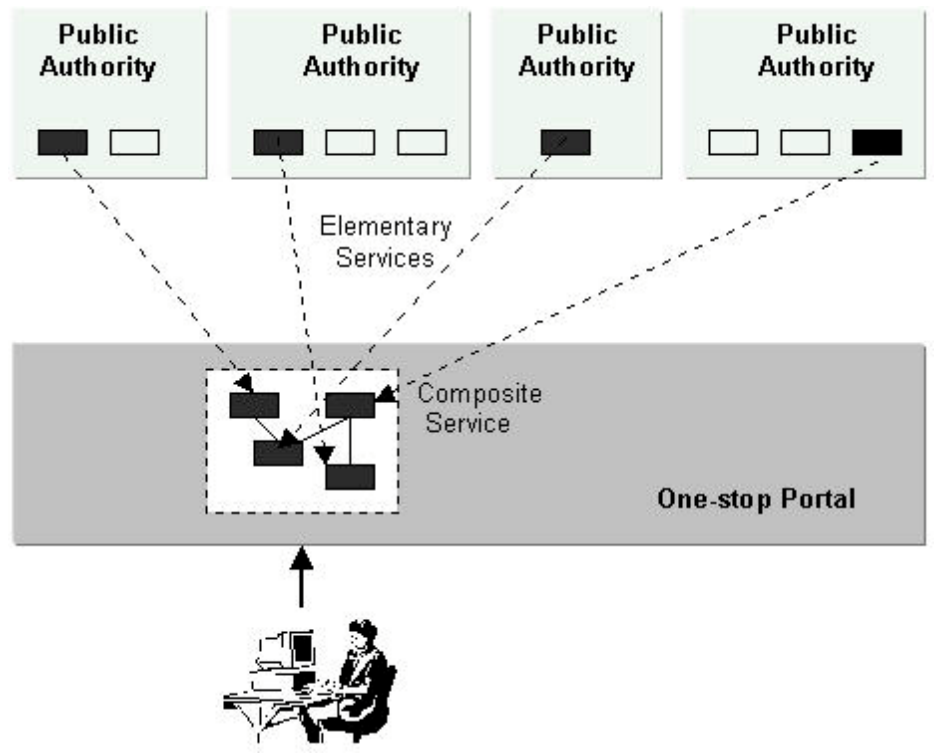

Fig. 1. Online one-stop government: integration of services

The scope of this paper is to investigate the provision of services to the public via a one-stop government portal, focusing on the implications of developing and executing integrated services. In the following sections the lifecycle of integrated services will be analysed, i.e. the development, the provision and the execution phase, focusing on the effects the joining-up of services has on the involved public authorities (business processes, internal organisation etc).

In this paper integrated services will be called "composite services" as opposed to the term "elementary services" that will be used to refer to public services provided 
by a single public authority. Several elementary services are joined together according to specific operations flows in order to produce a composite service.

\section{Integration of Services}

The current trend in e-Government calls for joined-up services that are effective, simple to use, shaped around and responding to the needs of the users (i.e. people's everyday lives and/or daily businesses situations) and are not merely arranged for the provider's convenience. In this way, the users need have no knowledge of or direct interaction with the involved structures of government in order to conduct their business. Back-office interoperability becomes a key enabler of e-Government. Government entities need to be interoperable, in order to allow for data and information to be exchanged and processed seamlessly across government.

In order for a one-stop government portal to be able to respond to the needs of the users, much more than the simple indexing of the public offerings of all government agencies is required. The need for "consumer-centric" services calls for solutions that will facilitate the creation of integrated services by joining together the service offerings of a number of government entities based on the use that the citizens make of them. Consequently critical to the success of e-Government is the development and adoption of new technologies to help manage information and the utilisation of open standards. In particular metadata technologies are expected to play an important role in this effort.

e-Government affects every aspect of how an organisation delivers services to the public: the technological means, the business processes and the human resources. Consequently realising the full potential of e-Government is not merely about bringing existing services online. It involves not only a profound transformation in the way government interacts with the governed, but also the reinvention of its internal processes and organisation and the coherent integration of government infrastructure, systems, processes and services.

In the light of the above, the development of integrated services by completely redesigning business processes from a customer's point of view, is considered to be a non-viable approach, since this would translate into a massive process reengineering wave sweeping across government and calling for the radical reorganisation of public administration (the reassigning of responsibilities, the elimination of redundant processes, the modification of organisational structures etc).

A more viable solution would be to allocate the joining-up of services to the onestop government portal, maintaining the consolidated configuration of government and the existing assignment of responsibilities and optimising services on an elementary service level (intra-organisation business process reengineering). This means that the internal business processes associated with each elementary service have to be modelled and redesigned, in order to transform traditional processes to one-stop government processes.

The joining up of services at the one-stop government portal can be achieved though the introduction of an integration layer that will be responsible (a) for the joining together of services originating from different public authorities and (b) for the administration of the resulting composite services. 
This approach was followed in the framework of eGOV [5], a project that was financially supported by the European Commission under the Information Society Technologies Programme and whose aim was to specify, develop, deploy and demonstrate an integrated platform for realising online one-stop government.

The structure of such a one-stop government platform can be depicted in the form of a three-tier architecture comprising the following layers:

- Communication Layer

- Integration Layer

- Back-office Layer

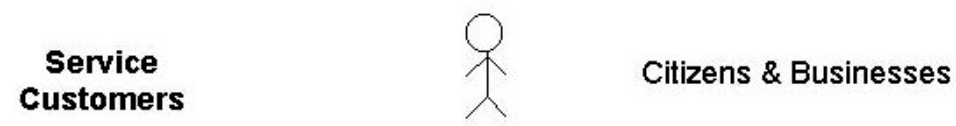

\section{Communication \\ Layer}

One-stop access to services

\begin{tabular}{|c|c|}
\hline $\begin{array}{c}\text { Integration } \\
\text { Layer }\end{array}$ & Integration of services \\
\hline
\end{tabular}

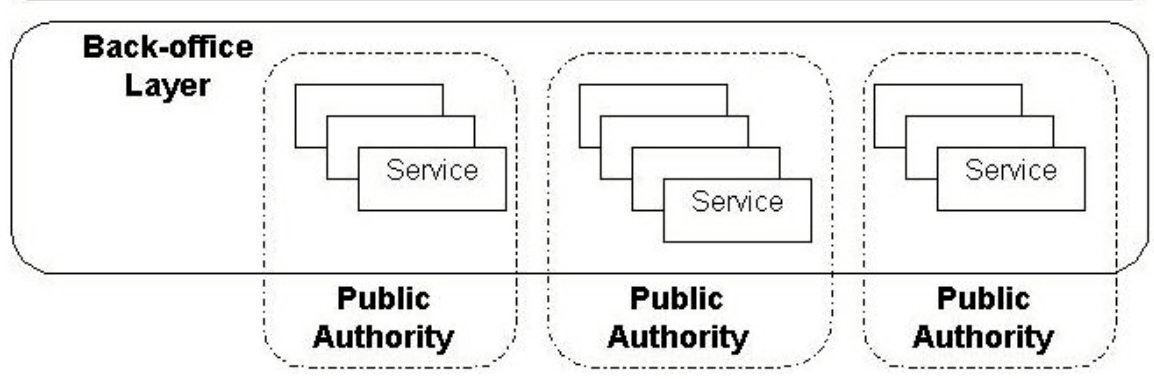

Fig. 2. One-stop government portal

\subsection{Communication Layer}

The communication layer represents the front-office of the integrated e-Government system, i.e. the one-stop point of access to the public offerings of all sectors and all levels of government.

In order to realise the full benefits from ICT, the integrated e-Government system must allow users to have:

- One-stop access

The integrated e-Government system must aggregate the offerings of different government entities. Users must be able to access public services via a single point of entry even if the services are provided by different departments or authorities. All government services which can be practically and legitimately delivered electronically should be available via the one-stop government portal. 


\section{- Seamless access}

Users do not need to know how government is organised or which department is responsible for the service that they require. Information and services must be organised in a way, which is both convenient and logical to users.

- Ubiquitous access

The system must support multiple delivery channels, such as call centres, Internet, mobile devices, satellite TV etc, as well as traditional walk-in centres for those who choose not to use online services. Users must be able to obtain information, search and invoke the execution of public services anywhere, anytime.

\section{- Security and privacy}

The system must incorporate security mechanisms in order to protect users' information and privacy, by ensuring people accessing information and services are who they claim to be, that the information that they provide to government is protected, and is used with integrity etc.

- User-friendliness

The system must provide users with an easy-to-use, intuitive interface, capable of accommodating both IT literate and first time users.

\subsection{Integration Layer}

The integration layer is responsible for developing composite services and for managing their execution. In this light, the integration layer is the core component of the one-stop portal, representing the instrument for coupling the front end with the back office.

Life events and business situations are mapped on composite services and composite services are analysed into elementary services. Being at the centre of this process, the integration layer deals with both the structuring and the decomposition of composite services. Consequently, all knowledge associated with a composite service resides at the integration layer: the list of elementary services that are associated with each composite service, the public authorities that are responsible for their execution, the sequence of execution of the elementary services, the required inputs of and the outputs produced by each elementary service etc. In this sense the one-stop government portal could be regarded as a knowledge management system.

The integration layer makes use of the accumulated knowledge in order to provide composite services to the users and to manage the execution of elementary services.

Two-way transparency is required:

- Administrative processes have to be made transparent to the user (the requestor of the composite service).

- Composite services have to be made transparent to the providers of the involved elementary services (the public authorities) 


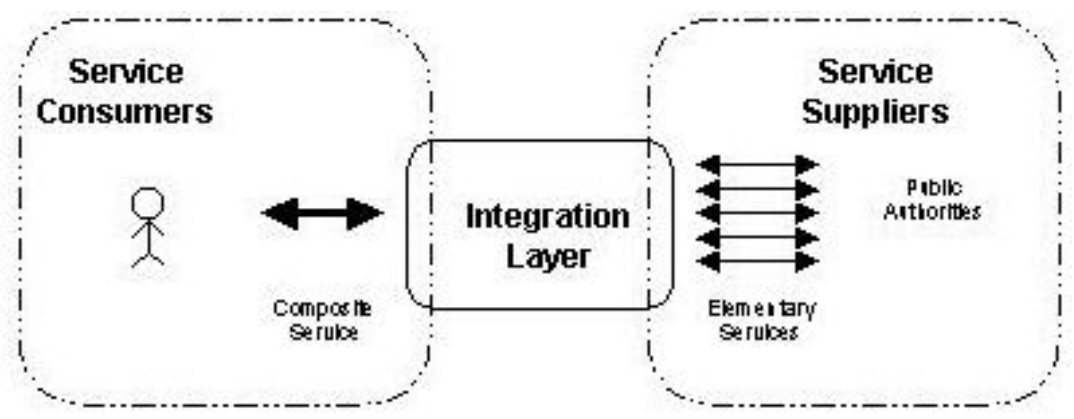

Fig. 3. Role of the integration layer of the one-stop government portal

Technologically the creation of one-stop portals to serve as marketplaces for integrated public services is facilitated by the development of standards like the Web Services Description Language (WSDL). WSDL is an XML (Extensible Markup Language) vocabulary that standardises the description of Web services defining them as collections of endpoints that exchange information about each others' capabilities thus allowing for inter-applications communication. Existing applications can be transformed into web services, while more sophisticated web services can be created from the combination of multiple backend applications related services based on defined operations flows.

Web services enable the development of e-Government platforms that act as intermediaries between the citizen and the government, (a) combining service offerings from multiple authorities into composite services that adhere to the citizen's everyday life necessities and (b) handling the execution of a series of services upon the invocation of a composite service at the portal.

Web services create a common language for the integration of services, while the actual service implementation is regarded as a "black box", i.e. it is of no importance whether the service is executed electronically (automated service execution) or not (non-automated service execution).

\subsection{Back-Office Layer}

The back-office layer is where the elementary services reside. In the case of automated service execution, service requests are handled electronically, without human interference. In other words the execution of the elementary service is undertaken by a fully automated back office system (legacy systems).

When services are executed automatically within legacy systems a S/W interface component "connects" the e-Government system with the automated service execution system of the local authority. This component receives the service input from the system and returns the service output after the service execution is completed. If it the local legacy system and the e-Government system are not interoperable, manual intervention is required for the execution of the service.

When automated service execution is not supported, the execution request together with all the necessary input data is passed to an employee, who initiates the backoffice process. This back-office process may consist of several tasks performed 
manually and/or involving the use of legacy systems (manual or partly automated back office processes).

In the case, where the service execution is performed manually, some kind of interface must be implemented in order to allow the local service administrator to interact with the e-Government system. By means of this interface the administrator is notified about incoming service execution requests and is provided with all the input data that is needed for the execution of these services.

Each local service administrator has complete knowledge of the service he/she is requested to execute (the input required, the local tasks involved, the output produced etc), but needs have no knowledge of the overall process the user has initiated at the one-stop portal (i.e. the invoked composite service).

\section{Execution of Integrated Services}

The aim of this section is to investigate the execution of integrated public services. For this purpose we shall examine a composite service modelled after the life-episode "marriage at the civil office" as performed in Greece ${ }^{1}$ in a non-automated service execution environment.

Table 1.

\begin{tabular}{|c|l|l|}
\hline Service & \multicolumn{1}{|c|}{ Description } & \multicolumn{1}{|c|}{ Responsible Public Authority } \\
\hline S1 & "Getting Birth Certificate" & $\begin{array}{l}\text { - } \\
\text { Municipality of birth of the bride } \\
\text { Municipality of birth of the } \\
\text { groom }\end{array}$ \\
\hline S2 & "Getting Marriage License" & $\begin{array}{l}\text { Municipality of residence of the } \\
\text { bride } \\
\text { Municipality of residence of the } \\
\text { groom }\end{array}$ \\
\hline S3 & "Arranging marriage date" & $\begin{array}{l}\text { Municipality in which the wedding } \\
\text { ceremony will take place }\end{array}$ \\
\hline S4 & "Getting Marriage Accom- & $\begin{array}{l}\text { Municipality in which the wedding } \\
\text { plishment Certificate" }\end{array}$ \\
\hline
\end{tabular}

In Greece, in order for a couple to get married at the civil office, the future husband and wife must each be in possession of a marriage license. A marriage license is a certificate that can be obtained at the person's municipality of residence. In order to apply for a marriage license a person needs to submit a registry action of birth, a certificate that is issued by the registry office of his/her municipality of birth. With the two marriage licenses in hand, the couple must visit the municipality where they wish the marriage ceremony to take place and arrange for a date for the event. After the end of the ceremony a "marriage accomplishment" certificate is issued.

The aforementioned process that could involve up to five different municipalities can be analysed in a sequence of composite and elementary services, some of which

\footnotetext{
${ }^{1}$ The process has been simplified.
} 
are performed twice (one time for the bride and one for the groom). Table 1 lists the authorities that are responsible for the execution of each service.

The service execution sequence is depicted in Figure 4:

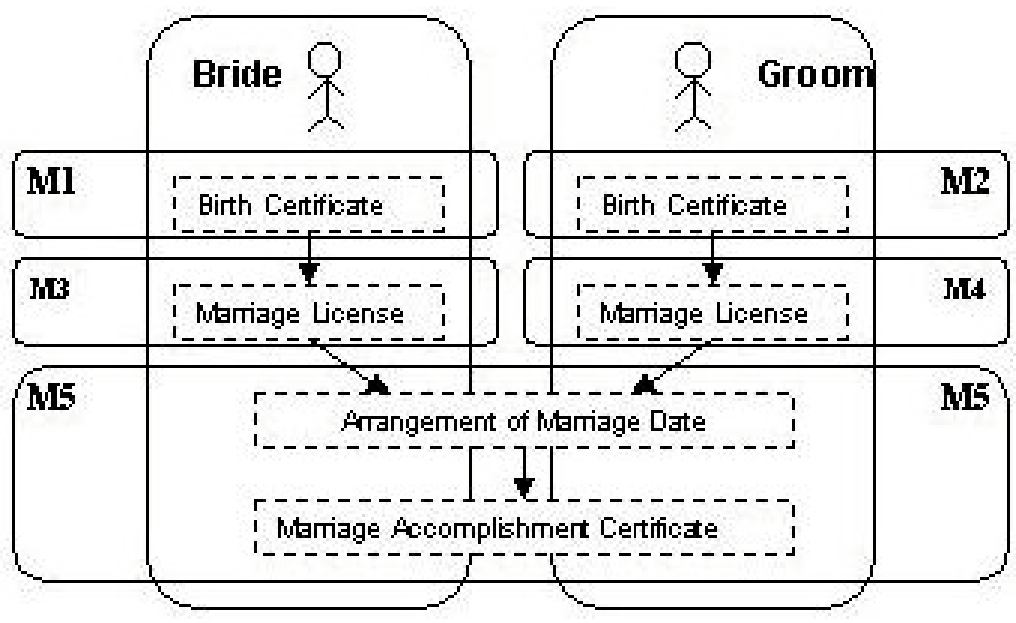

Fig. 4. Service execution sequence

It is evident that Elementary Service 1 (S1, "Getting birth certificate") at the municipality $\mathrm{Nr} 1$ (M1) and S1 at the municipality $\mathrm{Nr} 2$ (M2) are independent from each other and can be executed in parallel: the requests for the issuing of birth certificates can be processed at the same time by the related municipalities.

Each municipality will receive via the system a service execution request accompanied by the input that was provided by the requestor (i.e. personal data that correspond to the fields of the "regular" application form one would have to fill out at the City Hall for the issuance of a birth certificate).

Elementary Service 2 (S2, "Getting marriage licence"), apart from the requestor's personal data, also requires the submission of a number of accompanying documents that include his/her birth certificate (i.e. the end product of S1):

S2 at the municipality $\mathrm{Nr} 3$ (M3) cannot start before the successful completion of S1 at M1 although its beginning should not necessarily coincide with that of S2 at M4 (for the same reasons S2 at M4 should follow the execution of S1 at M2 but should not necessarily begin at the same time with S2 at M3).

All required documents for the issuing of a marriage licence are submitted by the citizen and controlled by the system upon invocation of the "civil marriage" service. However it is only after the birth certificate has been issued that M3 should receive the request for the issuing of a marriage licence (accompanied by all the prerequisites mentioned above).

In any case S3 (at M5) cannot start before the completion of both instances of S2 (at M3 \& M4): the two citizens must have obtained their marriage licences before they can make a request at the Municipality for the fixing of a date for the wedding ceremony. 


\subsection{Transparency}

From the point of view of any given authority involved in this process it is clear that its tasks are independent of those of the other authorities and that the system (i.e. the integration layer) should hide away the complexity of the execution of the "civil marriage" service.

The public employees monitoring the incoming service execution requests at the involved municipalities need not necessarily be aware that the "civil marriage" service is being executed. What is of importance is that the system provides them with input that will allow the responsible local department(-s) to handle the incoming service execution request.

The involvement of each authority in the "civil marriage" service starts with the arrival of the elementary service execution request and ends with the completion of its tasks (i.e. the elementary service it has been asked to execute).

In other words at some point of the "civil marriage" service execution all involved authorities are prompted by the system to perform a specific task, using input that was provided by the citizen and/or the results of other tasks (services) performed earlier by other authorities. Following the ordering of the "civil marriage" service through the one-stop portal, S1 will be invoked at M1 and M2, where the respective system administrators will have to respond to this request by launching the back-office process for issuing a birth certificate. The end product of this process (the birth certificate) is used as input for $\mathrm{S} 2$, together with all the other foreseen prerequisites.

\subsection{Service Execution Parameters}

The introduction of "unified" data submission forms at the portal side is of paramount importance for e-Government platforms offering integrated services, in order to avoid data redundancy and thus to promote user convenience. The entry fields of these forms should correspond to the service execution parameters of all the elementary services that form the invoked composite service. However the citizen should be prompted by the system only once to provide input that is common to more than one elementary services. For example in the case of the "civil marriage" scenario, not avoiding input data redundancy, would cause the two applicants to fill in their personal data (name, address, place and date of birth etc) two or three times.

This process is subsequently reversed at the service execution level, where the "unified" data submission forms are deconstructed and each authority involved receives all the data needed for the execution of its specific service.

\subsection{Notification}

Upon successful completion of an intermediary service (i.e. an elementary service forming part of the invoked composite service) the local service administrator has to notify the system that the process was concluded so that the execution of the following sub-service can begin.

The system and the central administrator must also be notified in case of service execution failure, which would cause the whole composite service execution to abort. The elementary service interface should allow the local administrator to report the 
reasons that have hindered service execution. Depending on their nature the reasons that caused the elementary service to abort should also be made known to the service requestor.

In any case the local service administrator should be able provide feedback to the system with regards to the execution of the elementary service.

\subsection{Delivery}

After the successful execution of service S4 at M5 the end product of the invoked "civil marriage" service (i.e. a "marriage accomplishment" certificate) is produced.

Via the elementary service interface the local administrator at M5 notifies the system about the successful completion of the process and/or forwards a copy of the certificate in picture format to the service requestor.

The original "marriage accomplishment" certificate may be sent to the applicant via regular mail or using any other delivery method the citizen has selected among the ones that are available.

In case multiple delivery channels are supported for a specific service, the requestor's preference must be conveyed by the system to the local administrator and through him/her to the responsible department of M5.

Particular attention should be given to the way the end products of the intermediary services are handled, since they only serve as input to some subsequent service and are not of interest to the composite service requestor (such is the case of the birth certificate in the "civil marriage" example). From this point on the end products of the intermediary services will be called intermediary products (of the composite service).

Should a local authority X (Auth. X) forward its end-product (Product X) directly to the authority Y (Auth. Y) that needs it as an input for the execution of the following service? Would a notification sent to Auth. Y via the system regarding the successful completion of the previous service be sufficient? Should intermediary products be delivered to the applicant as well?

According to today's common practice and the regulating legal framework, the employees of Auth. Y would need to have all input before hand (including the certificate produced by Auth. X) in order to execute their tasks (associated with the requested service). However in an integrated one-stop e-Government environment, it is clear that it would be more convenient to "substitute" intermediary products with internal certificates. The system could send Auth. Y the service execution request accompanied by all the required input, except of Product X (i.e. the end-product of the previous service executed at Auth. X). Instead of that Auth. Y would receive a certificate created by the system confirming that Product $\mathrm{X}$ has been produced and containing all the parameters that are associated with or are included in Product $\mathrm{X}$ and are of use to Auth. Y for the execution of its tasks.

In case Product $\mathrm{X}$ is a certificate, a copy of the certificate in picture format could be forwarded to Auth .Y or a legally binding "message" containing a copy of the certificate's content, the date it was issued the details of the person who signed the original document etc.

It is clear that the public servant at the local authority, not only must be able to notify the system about the successful completion of the service, but he/she must be in position to transfer the outcome of the service back to the system for further use, if 
not in the form it was produced, at least all useful (to the following service) parameters that are associated with it.

This could require the introduction of electronic reply forms at the e-Government system - local service administrator interface, allowing the public employee to fill in all the required parameters that would then be forwarded to the next authority.

\subsection{Controls}

It should be noted that some tasks that are performed at the portal side upon service invocation, such as user authentication, qualification checks of service prerequisites etc, can simplify the process that has to be followed at the public authorities and thus relieve them from a considerable overhead of traditional service execution. However in order to ensure the legal validity of the process all controls and qualification checks performed at the portal should be reported to the local authority executing the elementary service.

\section{Conclusions}

In this paper the concept of joined-up government was investigated from the point of view of the public administration.

The development of a unified access point to public services, where various public authorities collaborate for the provision of integrated services, can help reduce the inconvenience that customers face as a result of the strict division into sectors and spheres of responsibility in central and local government.

The improvement of customer services implies the redesigning of public services from a customer's point of view as part of an overall transformation of government from an "administrative" to a "service-oriented state".

This concept requires the reorganisation of the public sector and the reengineering of its processes. Connectivity and interoperability are key enablers in this effort. Critical to the success of e-Government is the development and adoption of new technologies to help manage information and the utilisation of open standards.

\section{References}

1. Accenture 2002, 'eGovernment Leadership: Realising the vision', company report available at http://www.accenture.com/xd/xd.asp?it=enWeb\&xd=industries\%5Cgovernment $\% 5$ Cgove_welcome.xml

2. Arthur Andersen 2001, "eGovernment. Anwendung der neuen Informations- und Kommunikationstechnologien durch die öffentliche Hand" company report

3. Deloitte Research 2000, "At the Dawn of E-Government. The Citizen as Customer" company report, available at http://www.deloitte.com

4. The Council for Excellence in Government 2001, Booklet 2.5 "E-Government: The next American Revolution", available at http://www.digitalgovernment.org/archive/library/pdf/wingo-egov.pdf 
5. EGOV Project, "An Integrated Platform for Realising Online One-Stop Government", project home-page available at www.egov-project.org

6. eEurope 2002, An information Society for All Action Plan, available at http://www.eeuropestandards.org/Docs/eeurope_initiative.pdf

7. European Commission 2003, "The Role of eGovernment for Europe's Future" communication to the European Council available at http://europa.eu.int/information_society/eeurope/2005/doc/all_about/egov_communication _en.pdf

8. EzGov FlexFoundation 2002, 'Perspectives. The Successful Road to E-government, available at www.ezgov.com

9. EzGov FlexFoundation, 'Realizing E-Government', White paper, available at www.ezgov.com

10. KPMG Consulting 2001, "E-Government for all" company survey available at http://www.kpmgconsulting.co.uk/research/reports/ps_egov0401.html

11. KPMG Consulting 2002, Is Britain on course for 2005?" company survey available at http://www.kpmgconsulting.co.uk/research/reports/ps_egov02.html

12. KPMG Consulting 2000, "Leading the transformation to E-Government" company report, available at http://www.kpmgconsulting.com/library/pdfs/egovernment_transformation.pdf

13. Lenk K., Tranmüller R., 2000, "A Framework for Electronic Government”, DEXA 2000, IEEE Press, pp. 271-277.

14. Tambouris E., 2001 'An Integrated Platform for Realising One-Stop Government: The eGOV project', DEXA 2001, IEEE Press Computer Society Press, Los Alamitos, CA, 2001, pp. 359-363.

15. UK Modernising Government secretariat 1999, "Modernising Government" report presented to UK Parliament by the Prime Minister and the Minister for the Cabinet Office

16. World Wide Web Consortium (W3C), "Web Services Description Language (WSDL) 1.1", W3C note, available at http://www.w3.org/TR/wsdl

17. World Wide Web Consortium (W3C), "Extensible Markup Language (XML)" W3C Recommendation available at http://www.w3.org/TR/REC-xml 